\title{
Pulmonary Arterial Hypertension in Women
}

\author{
Humna Abid Memon, M.D.; Myung H. Park, M.D. \\ HOUSTON METHODIST HOSPITAL, HOUSTON, TEXAS
}

\begin{abstract}
Pulmonary arterial hypertension (PAH) is characterized by pathological hemodynamic elevation in pulmonary artery pressure. Development of international registries over the last decade has raised awareness about the disease, leading to the development of new and improved therapies. Paradigm shifts such as these warrant review of existing literature regarding PAH, especially in females, as the disease continues to affect women more than males. The aim of this review is to provide an update on the classification, pathophysiology, diagnosis, and treatment of PAH while focusing specifically on its impact on women.
\end{abstract}

\section{INTRODUCTION}

Pulmonary hypertension $(\mathrm{PH})$ is characterized by an elevation in pulmonary artery (PA) pressure due to various cardiopulmonary diseases. A resting mean pulmonary artery pressure (mPAP) of $14 \pm 3 \mathrm{~mm} \mathrm{Hg}$ is considered normal, whereas $\mathrm{PH}$ is defined as $\mathrm{mPAP} \geq 25 \mathrm{~mm} \mathrm{Hg} .^{1,2}$ Pulmonary arterial hypertension (PAH) includes a heterogeneous group of disorders characterized by pulmonary vascular remodeling that leads to right heart failure (RHF). It is defined hemodynamically by the presence of precapillary $\mathrm{PH}$ with a $\mathrm{mPAP} \geq 25 \mathrm{~mm} \mathrm{Hg}$, pulmonary artery wedge pressure (PAWP) $<15 \mathrm{~mm} \mathrm{Hg}$, and pulmonary venous resistance (PVR) > 3 Wood units. ${ }^{2}$ This review discusses the classification, pathophysiology, diagnosis, and treatment of $\mathrm{PAH}$ with a special focus on women.

\section{CLASSIFICATION}

Previously classified as either primary or secondary $\mathrm{PH}^{3}$ classification of $\mathrm{PH}$ has now evolved to allow different types of $\mathrm{PH}$ to be grouped together based on similar pathophysiology and responses to treatment (Table 1). ${ }^{4}$ Modifications have led to the current five-group classification of $\mathrm{PH}$, with $\mathrm{PAH}$ designated as Group $1 \mathrm{PH} .{ }^{4} \mathrm{PAH}$ is subcategorized into the following four causes based on the underlying etiology driving the vascular remodeling: idiopathic PAH (IPAH); heritable PAH (HPAH); drug- and toxin-induced $\mathrm{PAH}$, and $\mathrm{PAH}$ associated with conditions such as connective tissue disease (CTD), HIV infection, portal hypertension, congenital heart disease (CHD), and schistosomiasis. ${ }^{4}$

\section{EPIDEMIOLOGY}

Pulmonary artery hypertension is a rare disease with an annual incidence of 2 to 8 cases per million population. ${ }^{5-7}$ Populationbased incidence gauged from studies have estimated the prevalence of $\mathrm{PAH}$ to range from 15 cases per million in
France to 52 per million in Scotland. ${ }^{5,6}$ Current data regarding epidemiology and outcomes has been derived from registries. The prospective U.S. National Institutes of Health (NIH) 1987 registry reported the mean age of patients with IPAH as $36 \pm$ 15 years, with only $9 \%$ of the patients $>60$ years. ${ }^{8}$ In contrast, contemporary registries all report a higher mean age of patients with $\mathrm{PAH}$ and IPAH. The French registry found the mean age to be $52 \pm 15$ years, with $25 \%$ of patients with any form of $\mathrm{PAH}>60$ years. ${ }^{6}$ Similarly, the REVEAL registry (Registry to Evaluate Early and Long-term PAH Disease Management) noted a mean age of $53 \pm 14$ years for the same patients. ${ }^{9} \mathrm{~A}$ higher mean age in contemporary registries does not necessarily reflect a change in biological phenotype of PAH but, more likely, an increasing awareness of $\mathrm{PAH}$ as well as widespread availability of echocardiograms to aid in its diagnosis. Heart failure with preserved ejection fraction (HFpEF), which affects older individuals and relies on measurement of PAWP, is often misdiagnosed as $\mathrm{PAH}$ and may also contribute to the increased mean age.

Much is still unknown about racial predisposition of $\mathrm{PAH}$ as only few registries have explored this aspect. The $\mathrm{NIH}$ registry reported the distribution of its patients as $85.4 \%$ white, $12.3 \%$ African American, and 2.3\% Hispanic, and REVEAL found similar patterns of distribution. ${ }^{10}$ When adjusted for age and sex, the proportion of whites in REVEAL was found to be similar to the U.S. population. However, the same population was found to be overrepresented for African Americans (12.2\% vs 10.9\%) and underrepresented for Hispanic (8.9\% vs $11.5 \%$ ) and Asian/ Pacific Islander (3.3\% vs $4.3 \%)$ patients. $^{10}$

\section{GENDER-BASED EPIDEMIOLOGIC DIFFERENCES}

Both old and contemporary registries have shown that $\mathrm{PAH}$ predominantly affects females. The $\mathrm{NIH}$ cohort noted that females were 1.8 times more likely to be affected by $\mathrm{PAH}$ relative to their male counterparts. ${ }^{10}$ Both the REVEAL and 
1. Pulmonary arterial hypertension (PAH)

1.1 Idiopathic $\mathrm{PAH}$

1.2 Heritable PAH

1.2.1 BMPR2

1.2.2 ALK-1, ENG, SMAD9, CAV1, KCNK3

1.2.3 Unknown

1.3 Drug and toxin induced

1.4 Associated with:

1.4.1 Connective tissue disease

1.4.2 HIV infection

1.4.3 Portal hypertension

1.4.4 Congenital heart diseases

1.4.5 Schistosomiasis

1' Pulmonary veno-occlusive disease and/or pulmonary capillary hemangiomatosis

1" Persistent pulmonary hypertension of the newborn (PPHN)

2. Pulmonary hypertension due to left heart disease

2.1 Left ventricular systolic dysfunction

2.2 Left ventricular diastolic dysfunction

2.3 Valvular disease

2.4 Congenital/acquired left heart inflow/outflow tract obstruction and congenital cardiomyopathies

3. Pulmonary hypertension due to lung diseases and/or hypoxia

3.1 Chronic obstructive pulmonary disease

3.2 Interstitial lung disease

3.3 Other pulmonary diseases with mixed restrictive and obstructive pattern

\subsection{Sleep-disordered breathing}

3.5 Alveolar hypoventilation disorders

3.6 Chronic exposure to high altitude

3.7 Developmental lung diseases

\section{Chronic thromboembolic pulmonary hypertension (CTEPH)}

\section{Pulmonary hypertension with unclear multifactorial mechanisms}

5.1 Hematologic disorders: chronic hemolytic anemia, myeloproliferative disorders, splenectomy

5.2 Systemic disorders: sarcoidosis, pulmonary histiocytosis, lymphangioleiomyomatosis

5.3 Metabolic disorders: glycogen storage disease, Gaucher disease, thyroid disorders

5.4 Others: tumoral obstruction, fibrosing mediastinitis, chronic renal failure, segmental PH

Table 1.

Clinical classification of pulmonary hypertension and pulmonary artery hypertension. Adapted from consensus guidelines of the 5 th World Symposium held

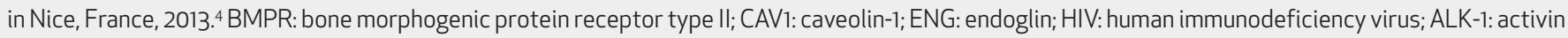
receptor-like kinase; SMAD9: mothers against decapentaplegic homolog 9; KCNK3: potassium channel subfamily K member 3 
the French registry found this ratio to be $3.6: 1$ and $1.9: 1$, respectively. ${ }^{10} \mathrm{It}$ is hypothesized that the stronger female predisposition seen in current U.S. registries may be secondary to the increased use of hormonal contraceptives in the 1980s.

The COMPERA (the Comparative, Prospective Registry of Newly Initiated Therapies for Pulmonary Hypertension) registry from Europe enrolled patients from 2007 to 2011 and noted a female predominance that decreased with increasing age. While an overall 1.8:1 female-to-male ratio was observed, the ratio was noted to be 2.3:1 in patients aged 18 to 65 years and 1.2:1 when only patients $>65$ years were analyzed. ${ }^{11}$ This difference in age and associated changes in hormonal milieu support the hypothesis of hormonal influence being key in $\mathrm{PAH}$ development.

Heritable PAH and IPAH occur twice as frequently in females compared to males. Similarly, PAH associated with CTD is reported to occur in a female-to-male ratio of 3.8:1. In addition, women with systemic sclerosis are eight times more likely than men to suffer from $\mathrm{PAH} .{ }^{6,12}$

\section{PROGNOSIS AND SURVIVAL}

Registries have been instrumental in determining survival for their individual cohorts and developing tools such as prognostic equations. As the first to assess mortality and only one to determine natural progression of $\mathrm{PAH}$, the $\mathrm{NIH}$ registry reported a 1 -year survival of $68 \%$ and mean survival of 2.8 years. $^{8}$ In the 19 years since this report, survival for $\mathrm{PAH}$ patients has improved. The French registry found 1-year survival of patients with PAH due to IPAH or with familial or anoreixgen-associated $\mathrm{PAH}$ to be $89.3 \%$, while the $\mathrm{NIH}$ equation projected it as $71.8 \% .{ }^{6}$ Similarly, the REVEAL registry demonstrated a 1-year survival of prevalent and newly diagnosed $\mathrm{PAH}$ patients as $90.4 \%$ and $86.3 \%$, respectively. ${ }^{13}$ Table 2 summarizes survival and incidence of PAH in these registries.

\section{GENDER-BASED DIFFERENCES IN PROGNOSIS}

Recent registries have shown that females with PAH have better survival compared to males. Both the REVEAL and the French registries demonstrated that males with PAH were twice as likely to die compared to females, irrespective of disease severity and surrogates such as 6-minute walk distance

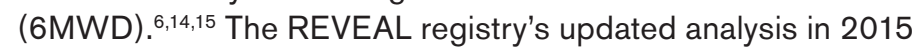
demonstrated that survival continued to favor women 5 years after enrollment. This gender-based difference in mortality was noted regardless of PAH being incident ( $53 \pm 4 \%$ vs $63 \pm 2 \%$ ) or prevalent ( $57 \pm 2 \%$ vs $68 \pm 1 \%) .^{13}$

\section{PATHOPHYSIOLOGY}

$\mathrm{PAH}$ is caused by changes in pulmonary vasculature that result in sustained vasoconstriction, pulmonary vascular remodeling, inflammation, and in situ thrombosis within the small pulmonary arteries and arterioles. Histologically, all arterial layers undergo changes in PAH that lead to development of intimal hyperplasia, medial hypertrophy, adventitial proliferation, and in situ thrombosis..$^{16-18}$ Furthermore, endothelial cells can undergo uncontrolled replication to create plexiform lesions that are pathognomonic for $\mathrm{PAH}$.

Endothelial dysfunction in PAH also affects the relative proportions of vasoconstrictors to vasodilators. Levels of vasoconstrictors such as thromboxane, endothelin, and serotonin tend to be higher compared to vasodilatory substances such as prostacyclin, nitric oxide (NO), and vasoactive intestinal polypeptide, causing increased resistance in the pulmonary vasculature. ${ }^{19,20}$

Prostacyclin is a potent vasodilator and inhibits platelet aggregation and smooth muscle proliferation. Studies have demonstrated decreased production of prostacyclin in patients with PAH compared to controls. ${ }^{19}$ Similarly, NO produced by nitric oxide synthetase (NOS) within vessels causes vasodilation and inhibits platelet activation and vascular smooth muscle proliferation. Effects of NO are mediated by cyclic guanosine monophosphate (cGMP) that is inactivated by phosphodiesterase. Patients with PAH have decreased NOS activity and NO bioavailability, thus leading to vasoconstriction. ${ }^{21}$ Endothelin-1 (ET-1), a smooth muscle mitogen, is the main vasoconstrictor in PAH. ${ }^{22}$ Plasma levels of ET-1 in PAH patients are usually increased and are shown to be inversely proportional to the degree of pulmonary blood flow and cardiac output. ${ }^{23}$

Pathological examination of PAs in PAH has shown the presence of inflammatory cell infiltrate and elevation in serum levels of inflammatory cytokines such as interleukin-1 (IL-1), IL-6, and tumor necrosis factor (TNF). Among these, IL- 6 has been studied the most. IL- 6 knock-out mice were found to be resistant to hypoxia-induced $\mathrm{PH}$, whereas increases in IL-6 expression led to $\mathrm{PH}^{24}$

\section{GENETIC PREDISPOSITION}

PAH occurs in genetically predisposed individuals. It is inherited as an autosomal dominant trait with variable penetrance, such that between $10 \%$ and $20 \%$ of patients with the concerned mutations develop $\mathrm{PAH} .{ }^{25} \mathrm{~A}$ major genetic pathway was attributed to the transforming growth factor beta (TGF- $\beta$ ) 


\begin{tabular}{|c|c|c|c|}
\hline \multirow{2}{*}{ REGISTRY } & \multirow{2}{*}{ POPULATION CHARACTERISTICS (\%) } & \multicolumn{2}{|l|}{ SURVIVAL } \\
\hline & & YEAR & $\%$ \\
\hline $\begin{array}{l}\text { NIH (1981-1988) } \\
(n=194)\end{array}$ & $\begin{array}{l}\text { IPAH (NA) } \\
\text { HPAH (NA) } \\
\text { Anorexigen (NA) }\end{array}$ & $\begin{array}{l}1 \\
3 \\
5\end{array}$ & $\begin{array}{l}68 \\
48 \\
34\end{array}$ \\
\hline $\begin{array}{l}\text { FRENCH }(2002-2003) \\
(\mathrm{n}=354)\end{array}$ & $\begin{array}{l}\operatorname{IPAH}(74.6) \\
\operatorname{HPAH}(7.3) \\
\text { Anorexigen (18.1) }\end{array}$ & $\begin{array}{l}1 \\
3 \\
5\end{array}$ & $\begin{array}{l}82.9 \\
67.1 \\
58.2\end{array}$ \\
\hline $\begin{array}{l}\text { REVEAL (2006) } \\
(n=2716)\end{array}$ & $\begin{array}{l}\text { IPAH (46.5) } \\
\text { HPAH (2.9) } \\
\text { CHD (11.8) } \\
\text { CTD (23.9) } \\
\text { Portal HTN (5.1) } \\
\text { Drugs/toxins (4.9) } \\
\text { HIV infection (1.9) } \\
\text { Other (3.1) }\end{array}$ & $\begin{array}{l}\text { 1-low risk } \\
\text { 1-average risk } \\
\text { 1-moderate high risk } \\
\text { 1-high risk } \\
\text { 1-very high risk }\end{array}$ & $\begin{array}{l}>95 \\
90-95 \\
85-90 \\
70-85 \\
<70\end{array}$ \\
\hline
\end{tabular}

Table 2.

Incidence and survival of pulmonary hypertension based on different registries. IPAH: idiopathic pulmonary arterial hypertension; HPAH: hereditary pulmonary arterial hypertension; CHD: congenital heart disease; CTD: connective tissue disease; HTN: hypertension; NA: not available

family. Serine/threonine receptor kinase encoded by the bone morphogenetic protein receptor type 2 (BMPR2) gene belongs to this family and is involved in the development of PAH in $75 \%$ of inherited cases. Mutations in BMPR2 affect signal transduction, leading to cellular proliferation. ${ }^{26}$ Another TGF- $\beta$ superfamily receptor implicated in patients with hereditary hemorrhagic telangiectasia and $\mathrm{PAH}$ is activin receptor-like kinase 1 (Alk1). ${ }^{26,27}$

\section{EFFECT OF ESTROGEN}

Estrogen affects the cardiopulmonary system through two receptors that have opposing effects: estrogen receptor (ER) $\alpha$ and $E R \beta{ }^{28} E R \alpha$ has pro-proliferative properties that have been associated with decreased expression of BMPR2 in model systems. ${ }^{29}$ Studies showing reduced expression of BMPR2 in patients with PAH, regardless of their genotype, have also demonstrated that the presence of estrogen predisposes to $\mathrm{PAH} .{ }^{30}$ In contrast, ER $\beta$ has antifibrotic, antiinflammatory, antihypertrophic, and vasodilatory properties in both the right ventricle and lungs. ${ }^{28}$ Thus, while the role of estrogen in the pathogenesis of PAH may be incompletely understood, experimental studies demonstrate that estrogen has an overall protective effect on the cardiovascular system. Concurrently, in light of the opposing action of the two estrogen receptors, the same studies also highlight the significance of creating estrogen receptor-specific $\mathrm{PAH}$ therapies. 


\section{RIGHT VENTRICULAR REMODELING}

Increased afterload in PAH leads to right ventricular (RV) remodeling and can result in $\mathrm{RV}$ failure if not treated. Based on the pressure-volume relationship of the heart in chronic $\mathrm{PAH}$, the right ventricle can adapt to elevations in load by increasing contractility to preserve cardiac output, which it does via concentric remodeling. However, persistently elevated PA pressures stretch the RV wall and add sarcomeres to the cardiomyocytes, which in turn leads to increased RV muscle mass and eventual adaptive hypertrophy. ${ }^{31}$ If ventricular pressures remain uncontrolled, adaptive hypertrophy leads to RV dilation. This results in RV-PA "uncoupling," in which the right ventricle is unable to respond to changes in the afterload. ${ }^{32}$ Right ventricular dilatation increases wall tension, creating a mismatch between oxygen supply and demand that is thought to be an important mechanism in RV uncoupling. Other major contributors to RV dysfunction include increased chronic activation of the sympathetic pathway, immune activation, cardiomyocyte apoptosis, and oxidative stress. ${ }^{31}$

The decline in RV function, increase in contraction time, and resulting ventricular asynchrony along with decreased RV stroke volume cause a decrease in left ventricular (LV) preload. Diminished LV filling can also be caused by leftward bowing of the interventricular septum stemming from a prolonged RV contraction time, which in turn triggers a decrease in LV volume during the early phase of diastole. This, together with RV systolic and diastolic dysfunction, causes a decline in cardiac output and subsequent right heart failure in uncontrolled severe $\mathrm{PAH}$. Hence, while RV remodeling may not be implicated in the initial pathogenesis of $\mathrm{PAH}$, it is integral to the subsequent progression of $\mathrm{PAH}$ and the patient's prognosis. ${ }^{32}$

\section{DIAGNOSIS}

Current guidelines recommend that patients with suspected $\mathrm{PAH}$ undergo a comprehensive diagnostic evaluation and early referral to a specialized $\mathrm{PH}$ center (Figure 1). ${ }^{33}$ The initial diagnostic evaluation requires (1) careful screening to determine the presence of risk factors, such as a history of connective tissue disease, liver disease, HIV, and exposure to known drugs and toxins (e.g., methamphetamine use), (2) a detailed family history, and (3) a thorough physical examination to look for signs and symptoms of $\mathrm{PH}$ and right heart failure. Additionally, the evaluation should include chest radiographs, electrocardiography, and basic laboratory testing inclusive of connective tissue disease and HIV serologies.

\section{ECHOCARDIOGRAPHY}

Echocardiography is the most important screening test as it provides essential information regarding cardiac features critical in diagnosing $\mathrm{PAH}$. It can determine tricuspid regurgitation (TR) jet velocity and, using Bernoulli's equation, derive an estimated pulmonary artery systolic pressure (PASP). Most importantly, it helps in RV assessment by measuring the size and function of both the right atrium and ventricle. Even so, echocardiogram has its limitations. Depending on the body habitus and the presence of parenchymal lung disease, TR jet velocity may not be adequate to assess PASP in around $60 \%$ of patients who undergo an echocardiogram. ${ }^{34}$ Furthermore, the RV's complex geometric shape and contractile motion make it difficult to assess right heart function. Nonetheless, enlarged and/or hypertrophied right heart chambers along with a flattened or D-shaped interventricular septum can indicate impaired right heart function..$^{35}$ In addition, fractional area change of the RV and tricuspid annular plane systolic excursion-the distance that the tricuspid annulus moves toward the RV apex during systolecan assist in determining RV function. ${ }^{36}$

\section{RIGHT HEART CATHETERIZATION}

Right heart catheterization (RHC) is necessary to establish a diagnosis, as the definition of $\mathrm{PAH}$ requires that certain hemodynamic parameters be met, including $\mathrm{mPAP} \geq 25 \mathrm{~mm}$ $\mathrm{Hg}, \mathrm{PAWP} \leq 15 \mathrm{~mm} \mathrm{Hg}$, and PVR $>3$ Wood units. ${ }^{4,37}$ While echocardiography is the key in screening, it lacks the accuracy to diagnose PAH. Accurate measurement of left-sided filling pressure (i.e., PAWP and/or left ventricular diastolic pressure) is critical in correctly diagnosing $\mathrm{PAH}$ and distinguishing it from pulmonary venous hypertension (PVH), classified as WHO Group $2 \mathrm{PH}$. No approved therapies for PVH exist, and PAHspecific treatments in this population can worsen heart failure symptoms. When determining PAWP, close attention must be paid to the timing and wave form characteristics to prevent misdiagnosing PVH as PAH. ${ }^{38}$ PAWP should be read at the end expiration phase rather than relying on the computer-generated mean pressure, which can be falsely low. ${ }^{38}$

Right heart catheterization is also needed to assess acute vasoreactivity to determine if the patient should be considered for treatment with high-dose calcium channel blockers.

Vasoreactivity is defined as a decrease in mPAP by at least 10 $\mathrm{mm} \mathrm{Hg}$ to reach an absolute value of $40 \mathrm{~mm} \mathrm{Hg}$ or less without a decrease in cardiac output. ${ }^{39}$ Agents used to determine vasoreactivity include inhaled NO, intravenous epoprostenol, or adenosine. Vasoreactivity testing is recommended in IPAH patients only, and development of pulmonary edema during the study should raise suspicion for other diagnoses. ${ }^{39}$

Since PAH patients most commonly present with dyspnea on exertion, provocative testing could also be performed during $\mathrm{RHC} .{ }^{2}$ Provocative testing involves a fluid challenge with 500 $\mathrm{mL}$ of normal saline over 5 to 10 minutes or exercise stress 


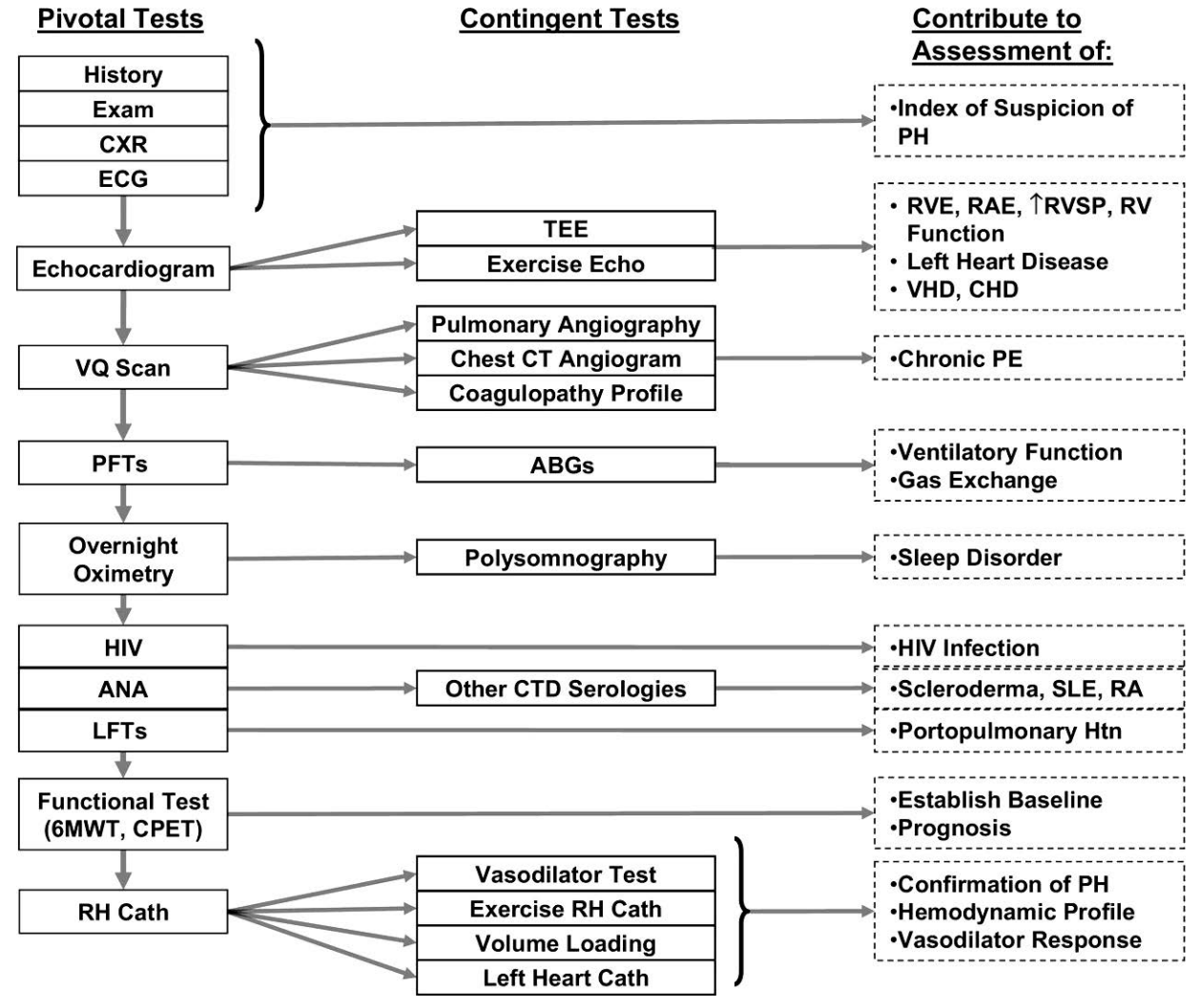

Figure 1.

Diagnostic approach to pulmonary artery hypertension (from the ACC/AHA 2009 Expert Consensus Document on Pulmonary Hypertension). ${ }^{33}$ 6MWT: 6-minute walk test; ABGs: arterial blood gases; ANA: antinuclear antibody serology; CHD: congenital heart disease; CPET: cardiopulmonary exercise test; CT: computerized tomography; CTD: connective tissue disease; CXR: chest x-ray; ECG: electrocardiogram; echo: echocardiogram; HIV: human immunodeficiency virus screening; HTN: hypertension; LFT: liver function test; PE: pulmonary embolism; PFT: pulmonary function test; $\mathrm{PH}$ : pulmonary hypertension; RA: rheumatoid arthritis; RAE: right atrial enlargement; RH Cath: right heart catheterization; RVE: right ventricular enlargement; RVSP: right ventricular systolic pressure; SLE: systemic lupus erythematosus; TEE: transesophageal echocardiography; VHD: valvular heart disease; VQ Scan: ventilationperfusion scintigram using a supine cycle ergometer, both of which are followed by repeat measurements of PAP, PAWP, and cardiac output. ${ }^{40}$ This type of testing can reveal hemodynamic abnormalities consistent with $\mathrm{PVH}$, which overlaps with and gets misdiagnosed as PAH.

\section{VENTILATION PERFUSION SCAN}

Patients suspected of having $\mathrm{PAH}$ should undergo a ventilation perfusion ( $\mathrm{V} / \mathrm{Q}$ ) scan to determine if the cause is chronic thromboembolic pulmonary hypertension (CTEPH). CTEPH is the only form of $\mathrm{PH}$ that is potentially curable through pulmonary thromboendarterectomy, a surgical procedure that removes organized thrombi from pulmonary arteries, decreases the obstruction and PVR, and restores RV function. While computed tomography (CT) pulmonary angiography is the imaging modality of choice to rule out acute pulmonary embolism, it lacks sensitivity and specificity to diagnose CTEPH. However, V/Q scan can rule out CTEPH if normal and prompt further testing if abnormal..$^{4,37}$

\section{CARDIAC MAGNETIC RESONANCE IMAGING}

Cardiac magnetic resonance imaging (CMR) can be used to evaluate RV structure and function as well as the pulmonary vascular bed and myocardium. With spatial resolution and freedom from acoustic windows, CMR is the gold standard for quantifying RV size and function. ${ }^{41,42}$ Limitations of CMR include cost, availability, long scan times, and incompatibility with indwelling hardware. Nonetheless, CMR not only plays an integral role in evaluating $\mathrm{PAH}$ but can also be used after administration of $\mathrm{PAH}$-specific therapy to track changes in RV size and function, both of which correlate strongly with survival in IPAH patients. ${ }^{43}$

\section{PULMONARY FUNCTION TESTS \& NIGHT OXIMETRY STUDY}

Pulmonary function tests (PFTs) help to exclude airway or lung parenchymal abnormalities as causes of $\mathrm{PH}$. PFTs in $\mathrm{PAH}$ can show mild to moderate reduction of lung volume, which correlates with disease severity. ${ }^{44,45}$ In $\mathrm{PAH}$, lung diffusion capacity for carbon monoxide (DLCO) may also be low, with a poor outcome noted in those with DLCO $<45 \% .{ }^{44,45}$ PFT findings in $\mathrm{PAH}$ overlap with other causes of $\mathrm{PH}$ such as interstitial lung disease, making interpretation of PFTs alongside imaging studies such as chest CT important. Due to high prevalence (70-80\%) of nocturnal hypoxemia and central sleep apnea in $\mathrm{PAH}$, nocturnal oximetry or polysomnography is also recommended to exclude sleep apnea in these patients. ${ }^{46,47}$ 


\section{PAH-SPECIFIC THERAPY}

Therapies specific to $\mathrm{PAH}$ exert their effect by augmenting deficient systems (prostacyclin and nitric oxide) or by blocking the endothelin pathway. Since each class and drug has its own unique side effects, treatment requires thoughtful consideration in choosing the initial therapy and close follow-up to assess response and efficacy.

\section{Prostanoids}

Epoprostenol. Epoprostenol (Flolan) improves functional class, exercise capacity, hemodynamics, and survival in IPAH patients compared to standard treatment, as demonstrated in a landmark randomized trial by Barst and colleagues..$^{48} \mathrm{It}$ is the only therapy shown to demonstrate survival benefit, making it the gold standard for treatment of PAH. ${ }^{48}$ Intravenous epoprostenol is also effective in treating PAH associated with CTD, HIV, congenital heart disease, and portopulmonary hypertension..$^{4}$ However, the short half-life ( $<6$ minutes) requires continued infusion through a tunneled catheter, making intravenous epoprostenol a challenging therapy to implement. Adverse effects of prostanoids are common and include flushing, headaches, jaw and joint pain, and diarrhea.

Treprostinil. Treprostinil (Remodulin) is a prostacyclin analogue that, due to its longer half-life of 4.5 hours and stability at room temperature, can be delivered through a subcutaneous, intravenous, inhaled, and oral route. The subcutaneous form was studied first and demonstrated a modest but statistically significant median increase in 6MWD of 16 meters as well as improved quality of life versus placebo. ${ }^{50}$ The main side effect of subcutaneous treprostinil is infusion site pain, which improves after proper dose escalation. ${ }^{51}$ Intravenous treprostinil was approved by the U.S. Food and Drug Administration (FDA) after a study demonstrated improvement in 6MWD and hemodynamics. ${ }^{52}$ Inhaled treprostinil (Tyvaso) is delivered via a proprietary inhaler 4 to 6 times a day. It was FDA approved after a randomized placebo-controlled study of $235 \mathrm{PAH}$ patients with active symptoms showed an improvement of $6 \mathrm{MWD}$ with the addition of inhaled treprostinil to oral bosentan or sildenafil. ${ }^{53}$

Oral treprostinil (Orenitram) is available as a sustainedrelease tablet administered twice daily. Results of the phase III FREEDOM-M placebo controlled study, which enrolled 228 treatment-naïve PAH patients, demonstrated significant improvement in median 6MWD. ${ }^{54}$ However, the FREEDOM-C(2) trial, which enrolled $310 \mathrm{PAH}$ patients receiving background treatment with an endothelin receptor antagonist (ERA) and/or phosphodiesterase type 5 (PDE-5) inhibitors, did not meet the primary end point of significant improvement in 6MWD. ${ }^{55}$ Enrollment for a clinical trial assessing efficacy of oral treprostinil given three times daily is currently underway.

Iloprost. Inhaled iloprost (Ventavis) was the first inhaled therapy approved for PAH after a placebo-controlled randomized trial of 207 patients met a composite end point of improvement in functional class by at least one level and increase in $6 \mathrm{MWD}$ by at least $10 \% .^{56}$ Due to its short half-life, inhaled iloprost is administered 6 to 9 times daily with cough being its most commonly reported side effect.

Selexipag. Selexipag is an oral prostacyclin IP receptor agonist that is hydrolyzed by enzymes to an active metabolite with a half-life of about 8 hours. ${ }^{57,58} \mathrm{~A}$ phase II study demonstrated that selexipag not only decreased PVR but was also well tolerated at doses less than $800 \mathrm{mg}$ twice daily. ${ }^{59} \mathrm{In}$ the pivotal GRIPHON trial, 1,156 patients were randomized to receive placebo or selexipag in 1:1 design, with $80 \%$ of the patients on background treatment with endothelin receptor antagonists and/or PDE-5 inhibitors. This study demonstrated a significant decrease in morbidity irrespective of background therapy. ${ }^{60}$

\section{Endothelin Receptor Antagonists}

Endothelin receptor antagonists are orally active medications that bind to endothelin receptors $A$ and $B$ in the PA smooth muscle.

Bosentan. A dual endothelin receptor blocker, bosentan (Tracleer) was the first oral therapy to be approved for PAH in 2001. BREATHE-1 studied bosentan in a placebo-controlled trial with a primary end point of change in GMWD and secondary end point of time to clinical worsening, which was defined as time to death, lung transplantation, hospitalization for $\mathrm{PH}$, lack of clinical improvement, need for epoprostenol therapy, or atrial septostomy. After 16 weeks, treatment with bosentan showed a significant increase in $6 \mathrm{MWD}$ and delay in time to clinical worsening. Bosentan is metabolized by the P450 enzyme systems, hence its primary side effect is an increase in hepatic transaminases that is dose dependent and reversible. ${ }^{61}$ Therefore, liver function tests are required before drug initiation and monthly thereafter. Bosentan has also been shown to have teratogenic effects in animals and may decrease efficacy of hormonal contraception in women. Thus, women using bosentan must be counseled to use concurrent barrier methods and not rely on oral contraception alone.

Ambrisentan. Ambrisentan (Letairis) is a relatively selective endothelin receptor antagonist that was studied in the ARIES I and II trials conducted in the United States and Europe/South America, respectively. ${ }^{62}$ These combined studies enrolled 
approximately 400 patients in a placebo-controlled trial and showed significant increases in 6MWD, delayed time to clinical worsening, and improvement in functional class. ${ }^{62}$ Major side effects of ambrisentan are peripheral edema and worsening heart failure symptoms, mostly in elderly patients with features of HFpEF. Unlike bosentan, ambrisentan is not hepatotoxic but is teratogenic.

Macitentan. Macitentan (Opsumit) is the most recent ERA approved for $\mathrm{PAH}$ and has enhanced tissue penetration. SERAPHIN, the first long-term, event-driven trial in $\mathrm{PAH}$, was a double-blind placebo controlled study with mortality and morbidity as the primary end point. Compared to placebo, macitentan demonstrated a reduction in events by $30 \%$ in the $3-\mathrm{mg}$ group $(97.5 \% \mathrm{Cl} 4-48 \% ; P=.0108)$ and $45 \%$ in the $10-\mathrm{mg}$ group $(97.5 \% \mathrm{Cl} 24-61 \% ; P=.0001)$, irrespective of background therapy. ${ }^{63}$ Macitentan also reduced the risk of mortality and hospitalization for $\mathrm{PAH}$ by $33 \%$ and $50 \%$ for the 3- and 10-mg groups, respectively. ${ }^{64} \mathrm{~A}$ macitentan dose of 10 mg once daily has been approved for WHO Group I PAH to delay disease progression. The incidence of liver transaminase elevation (i.e., greater than 3 times the upper limit of normal) in the SERAPHIN study was 3.4\% for macitentan and $4.5 \%$ for placebo. ${ }^{63}$ Liver function testing is recommended prior to initiation and should be repeated during therapy as clinically indicated. The main side effects of macitentan are anemia, nasopharyngitis, and headache.

\section{Phosphodiesterase-5 Inhibitors}

Phosphodiesterase-5 (PDE5) inhibitors act on the isoform of PDE5 within the pulmonary vasculature and cause vasodilation by increasing levels of cyclic guanosine monophosphate, which plays an important role in processes that influence vascular tone, endothelial cellular proliferation, and fibrosis.

Sildenafil. SUPER-1, a placebo-controlled trial, studied the effects of sildenafil (Revatio) in 278 patients with PAH. Improvement in 6MWD, functional class, and hemodynamics with no significant difference in incidence of clinical worsening was noted between the treated and placebo groups. ${ }^{65}$ Sildenafil was well tolerated, with side effects including headache and epistaxis. Visual disturbances reported in patients using sildenafil have raised concerns, especially among those with diabetes and cardiovascular risk factors. Nonetheless, no significant reports of ophthalmologic disturbances have been reported with chronic use in $\mathrm{PAH}$ patients.

Tadalafil. Tadalafil (Adcirca) is a selective PDE5 inhibitor approved after the randomized placebo-controlled PHIRST trial demonstrated improvement in 6MWD in a dose-dependent manner, with $40 \mathrm{mg}$ leading to a statistically significant increase in 6MWD and improvement in time to clinical worsening. ${ }^{66}$ Tadalafil has frequent side effects that include dose-related headache, myalgia, and flushing.

In a retrospective analysis of data from the PHIRST trial, Mathai et al. noted that men on tadalafil therapy were more likely to achieve a minimal important difference in 6MWD. ${ }^{67}$ In contrast, a pooled analysis of data collected from six randomized placebo-controlled trials demonstrated that treatment with ERA resulted in a 6MWD of $29.7 \mathrm{~m}$ greater in women compared to men. ${ }^{68}$ It is interesting to note this gender-based difference in treatment with ERA and tadalafil, as it demonstrates the heterogeneity of therapeutic responses to various classes of medications in the phenotypically diverse patients with $\mathrm{PAH}$.

\section{Soluble Guanylate Cyclase Stimulators}

Riociguat (Adempas) is an oral soluble guanylate cyclase stimulator (sGC) that produces more cyclic guanosine monophosphate by way of a dual mode of action. Riociguat sensitizes SGC to low levels of endogenous NO and, in the absence of NO, directly stimulates SGC via a different binding site ${ }^{69,70}$ Riociguat was studied in PATENT-1 in 445 treatmentnaïve $\mathrm{PAH}$ patients as well as those receiving ERAs or inhaled/ subcutaneous prostanoids. The results showed a significant increase in 6MWD and significant decreases in PVR $(P=$ $.0001)$ and clinical worsening $(P=.0046) .{ }^{69}$ Riociguat was also approved for inoperable CTEPH or recurrent $\mathrm{PH}$ after pulmonary thromboendarterectomy based on positive results from the CHEST-1 study, thereby becoming the only medical therapy for Group IV PH. ${ }^{70}$

\section{Calcium Channel Blockers}

Calcium channel blockers (CCBs) were the first group of agents to be used in PAH after early studies in the 1990s. ${ }^{71}$ However, acute vasoreactivity in most patients resulted in clinical decompensation and significant morbidity and mortality. ${ }^{72,73}$ In a recent analysis of 70 patients with IPAH who demonstrated acute vasoreactivity on CCBs, only $6.8 \%$ remained stable for more than 1 year. ${ }^{74}$ Based on hemodynamic comparison between patients who remained stable on CCBs and those who did not, CCBs can be considered as initial therapy in patients with IPAH but without RHF who demonstrate a favorable acute response, defined as a fall in mPAP of at least $10 \mathrm{~mm} \mathrm{Hg}$ to $40 \mathrm{~mm} \mathrm{Hg}$ or less with increased or unchanged cardiac output. ${ }^{33,72-74}$ Close follow-up to assess clinical response is critical in these patients so that $\mathrm{PAH}$ specific treatment can be initiated if functional class does not improve to I or II on CCBs. Among CCBs, amlodipine is the most commonly used agent, followed by diltiazem or long-acting nifedipine. 


\section{GUIDELINES FOR TREATMENT OF PAH}

Currently, there are two evidence-based, expert-consensus guidelines regarding treatment of $\mathrm{PAH}$. They differ primarily in their recommendations about upfront combination therapy. The 2014 CHEST guidelines for PAH suggest treatment based on the patient's functional class. ${ }^{75}$ The 2015 AMBITION trial advocates upfront initiation of combination treatment with ambrisentan and tadalafil and has become the basis of current recommendations for PAH patients. ${ }^{76}$ Since the CHEST guidelines were created prior to the release of AMBITION's results, they discuss the prospect of combination therapy but do not offer any strong recommendations. Rather, they suggest that functional class II or III patients with no evidence of disease progression start on oral monotherapy with an ERA, PDE5, or cGS stimulator with a "stepwise addition" approach. Additionally, functional class III patients who deteriorate despite oral monotherapy, those with rapid disease progression, and any functional class IV patients should be treated with prostacyclin infusion. ${ }^{75}$

The 2015 ESC/ERS guidelines equally recommend both stepwise initial monotherapy and upfront combination therapy with two or more agents. ${ }^{37}$ Although both approaches received Class I recommendation, only the combination of ambrisentan and tadalafil received Class I recommendation, with weaker recommendations for other dual combinations given the lack of supporting evidence. As there have been no direct comparisons between ERAs, PDE5 inhibitors, selexipag, and riociguat, all of them received Class I recommendations for use as monotherapy in functional class II and III patients. ${ }^{37}$

\section{PREGNANCY COUNSELING AND CONTRACEPTION IN PAH}

Pregnancy Counseling

Pregnancy is ill-advised and contraindicated in PAH due to high maternal and fetal mortality. ${ }^{37,77}$ Maternal survival and fetal outcomes are noted to be worse in patients with severe $\mathrm{PAH}$ compared to those with mild disease, with RHF being the main cause of poor outcomes. ${ }^{77,78}$ Pregnancy is associated with physiologic changes that increase pulmonary flow, such as increased circulating volume and cardiac output. Unlike normal pulmonary vasculature, the remodeled vasculature of a patient with PAH cannot accommodate and compensate for the increased pulmonary blood flow. $77,79,80$ Labor and childbirth cause further volume shifts and resultant hemodynamic changes that add stress to the already compromised right ventricle in $\mathrm{PAH}$ patients, resulting in worsening $\mathrm{PH}$ and $\mathrm{RHF} .{ }^{77,78}$ Although animal studies suggest that vasodilation from increased estrogen levels during pregnancy can improve RV function, the accompanying estrogen-induced proliferation of PA smooth muscle cells is thought to nullify this potential benefit. ${ }^{81}$ Hence, the risk for decompensation, RHF, and mortality in pregnant patients with $\mathrm{PAH}$ remains high, especially during the third trimester, between 20-24 weeks, and in the postpartum period. ${ }^{77}$

Given the heightened risk of fetal and maternal mortality in $\mathrm{PAH}$, patients and their families should be counseled regarding contraception and the need to avoid pregnancy as soon as $\mathrm{PAH}$ is diagnosed. Further assessment to determine individual risk during pregnancy should be conducted at a $\mathrm{PH}$ center experienced in managing pregnant women with $\mathrm{PAH}{ }^{37,77}$ Several contraception options for patients with PAH are discussed below.

\section{Contraceptive Methods}

Hormonal contraception is available in progestin-only or combined estrogen and progestin formulation. Use of contraceptives containing estrogen is relatively contraindicated in patients with $\mathrm{PAH}$ due to the increased risk of venous thromboembolism (VTE) associated with their use. ${ }^{77}$ Given that pulmonary embolism can be fatal in the setting of preexisting RV dysfunction, estrogencontaining contraceptives are avoided in PAH. Progestin-only contraception, however, is a suitable alternative for patients who cannot use permanent methods of contraception. Progestin-only contraception is available in the form of pills, injections, implants, and intrauterine devices (IUDs), although injections are generally avoided in PAH due to the increased risk of VTE. ${ }^{77}$ While prior data regarding this risk was conflicting, pooled data in a recent meta-analysis demonstrated that injectable progestin was associated with a 2-fold increase in risk of VTE. ${ }^{82}$ Progestin-only implants and IUDs are thus the preferred hormonal methods of contraception in PAH patients and are considered as safe and efficacious as surgical sterilization. ${ }^{77}$ Progestin-alone implants available in various formulations prove to be efficacious for varying durations (3-5 years).

An intrauterine device is another effective form of contraception in women with PAH. While both copper and progestin-releasing IUDs are available, the lower rate and amount of uterine bleeding associated with the progestin-releasing IUD makes it preferable to copper. While IUDs are safe for use in patients with $\mathrm{PAH}$, great caution should be exercised during placement as manipulation of the cervix can lead to vasovagal reactions that are difficult to resolve in these patients..$^{77}$ Several barrier methods including diaphragms and cervical caps can be used in patients with $\mathrm{PAH}$. However, given the high failure rate of these methods, they are not recommended as the only method of contraception in $\mathrm{PAH}$ patients. ${ }^{77}$

Since no temporary form of contraception is $100 \%$ effective, some $\mathrm{PH}$ centers favor permanent contraception such as tubal ligation or 
device implantation into the fallopian tube for their patients. These procedures require careful assessment and evaluation regarding the modes of anesthesia and surgical approach and should be done in a center with a multidisciplinary $\mathrm{PH}$ team.

\section{PREGNANCY MANAGEMENT IN WOMEN WITH PAH}

Despite counseling, patients with $\mathrm{PAH}$ may choose to become pregnant, or those with no prior diagnosis may present with an initial diagnosis of PAH during pregnancy. In either condition, elective termination of pregnancy should be offered regardless of their functional class. ${ }^{77}$ With the overall high risk in these patients, it is advised that therapeutic abortion be carried out at an experienced $\mathrm{PH}$ center. The procedure is safest when carried out in the first trimester but can be performed during the second trimester until fetal viability is achieved. ${ }^{77,83,84}$

If patients refuse termination, it is imperative that care be transitioned to a team of specialists that include a $\mathrm{PH}$ specialist, obstetrician, intensivist, and neonatologist at an experienced $\mathrm{PH}$ center. ${ }^{77,83}$ Close follow-up is advised to monitor the fetus for appropriate growth and the mother for worsening $\mathrm{PH}$, with the mother also receiving regular echocardiograms. ${ }^{77}$ Concurrent evaluation for lung transplantation, especially in high-risk patients, should be conducted as it may be warranted emergently in the event of decompensation. ${ }^{84}$ Given the increased risk of hemodynamic complications in the event of premature labor, it is not uncommon for patients to be preemptively hospitalized during the second trimester. ${ }^{78}$ Additionally, if indicated and required, early delivery after the second trimester should be considered in high-risk patients. ${ }^{77}$

According to ESC/ERS guidelines, it is essential to treat pregnant $\mathrm{PAH}$ patients with $\mathrm{PAH}$-specific medications. ${ }^{37}$ As ERAs have teratogenic side effects, their use during pregnancy is contraindicated in patients with $\mathrm{PAH}$. Once an appropriate regimen is determined, it is vital to continue monitoring and making adjustments to the dose since certain physiologic changes and complications of pregnancy can affect the absorption and bioavailability of these medications.

\section{CONCLUSION}

A greater understanding of $\mathrm{PAH}$, discovery of robust markers for prognostication, and new $\mathrm{PAH}$-specific therapies have led to improved survival and quality of life in women with $\mathrm{PAH}$. However, therapies for $\mathrm{PAH}$ are still riddled with limitations, hence PAH as a disease entity still remains largely incurable. Increased efforts aimed at early recognition and diagnosis of the disease and increasing our understanding of the mechanisms of RV failure are underway-measures that hopefully will lead to longer and better lives for our patients.

\section{KEY POINTS:}

- The development of the NIH registry has increased awareness and understanding of pulmonary arterial hypertension $(\mathrm{PAH})$, leading to new and improved $\mathrm{PAH}$-specific therapies and, in turn, improved survival compared to 20 years ago.

- Mortality in PAH remains high, and survival decreases further in women with PAH who choose to become pregnant.

- Pregnancy in PAH is ill-advised, and women with PAH should be counseled to use any of the effective contraception methods available.

- Patients with PAH who choose to pursue pregnancy should be referred to and managed at a pulmonary hypertension center under the care of experts experienced in treating such patients.

\section{Conflict of Interest Disclosure:}

The authors have completed and submitted the Methodist DeBakey

Cardiovascular Journal Conflict of Interest Statement and none were reported.

Keywords:

pulmonary artery hypertension, hypertension, women, pregnancy

\section{REFERENCES}

1. Kovacs G, Berghold A, Scheidl S, Olschewski H. Pulmonary arterial pressure during rest and exercise in healthy subjects: a systematic review. Eur Respir J. 2009 Oct;34(4):888-94.

2. Hoeper MM, Bogaard HJ, Condliffe R, et al. Definitions and diagnosis of pulmonary hypertension. J Am Coll Cardiol. 2013 Dec 24;62(25 Suppl):D42-D50.

3. Hatano S, Strasser T. Primary Pulmonary Hypertension. Report on a WHO meeting. World Health Organization meeting; 1973 Oct 15-17; Geneva, Switzerland.

4. Simonneau G, Gatzoulis MA, Adatia I, et al. Updated clinical classification of pulmonary hypertension. J Am Coll Cardiol. 2013 Dec 24;62(25 Suppl):D34-D41.

5. Peacock AJ, Murphy NF, McMurray JJ, Caballero L, Stewart S. An epidemiological study of pulmonary arterial hypertension. Eur Respir J. 2007 Jul; 30(1):104-9.

6. Humbert M, Sitbon O, Chaouat A, et al. Pulmonary arterial hypertension in France: results from a national registry. Am J Respir Crit Care Med. 2006 May 1;173(9):1023-30. 
7. Jansa P, Jarkovsky J, Al-Hiti H, et al. Epidemiology and long term survival of pulmonary arterial hypertension in the Czech Republic: a retrospective analysis of a nationwide registry. BMC Pulm Med. 2014 Mar 15;14:45.

8. Rich S, Dantzker DR, Ayres SM, et al. Primary pulmonary hypertension. A national prospective surgery. Ann Intern Med. 1987 Aug;107(2):216-23.

9. Badesch DB, Raskob GE, Elliot CG, et al. Pulmonary arterial hypertension: baseline characteristics from the REVEAL Registry. Chest. 2010 Feb;137(2):376-87.

10. Frost $A E$, Badesch DB, Barst RJ, et al. The changing picture of patients with pulmonary arterial hypertension in the United States: how REVEAL differs from historic and non-US contemporary registries. Chest. 2011 Jan;139(1):128-37.

11. Hoeper MM, Huscher D, Ghofrani HA, et al. Elderly patients diagnosed with idiopathic pulmonary arterial hypertension: results from the COMPERA registry. Int J Cardiol. 2013 Sep 30; 168(2):871-80.

12. Chung L, Farber HW, Benza R, et al. Unique predictors of mortality in patients with pulmonary arterial hypertension associated with systemic sclerosis in the REVEAL registry. Chest. 2014 Dec;146(6):1494-504.

13. Farber HW, Miller DP, Poms AD, et al. Five-year outcomes of patients enrolled in the REVEAL registry. Chest. 2015 Oct;148(4):1043-54.

14. Benza RL, Miller DP, Gomberg MM, et al. Predicting survival in pulmonary arterial hypertension: insights from the Registry to Evaluate Early and Long-Term Pulmonary Arterial Hypertension Disease Management (REVEAL). Circulation. 2010 Jul 13;122(2):164-72.

15. Humbert M, Sitbon O, Chaouat A, et al. Survival in patients with idiopathic, familial, and anorexigen-associated pulmonary arterial hypertension in the modern management era. Circulation. 2010 Jul 13;122(2):156-63.

16. Pletra GG, Capron F, Stewart S, et al. Pathologic assessment of vasculopathies in pulmonary hypertension. J Am Coll Cardiol. 2004 Jun 16;43(12 Suppl S):25S-32S.

17. Voelkel NF, Tuder RM, Weir EK. Pathophysiology of primary pulmonary hypertension. In: Rubin L, Rich S, editors. Primary pulmonary hypertension. New York: Marcel Dekker; 1997. p. 83-129.

18. Farber HW, Loscalzo J. Pulmonary arterial hypertension. N Engl J Med. 2004 Oct 14;351(16):1655-65.

19. Christman BW, McPherson CD, Newman JH, et al. An imbalance between the excretion of thromboxane and prostacyclin metabolites in pulmonary hypertension. N Engl J Med. 1992 Jul 9;327(2):70-5.
20. Stewart DJ, Levy RD, Cernacek P, Langleben D. Increased plasma endothelin-1 in pulmonary hypertension: marker or mediator of disease? Ann Intern Med. 1991 Mar; 114(6):464-9.

21. Ghofrani HA, Pepke-Zaba J, Barbera JA, et al. Nitric oxide pathway and phosphodiesterase inhibitors in pulmonary arterial hypertension. J Am Coll Cardiol. 2004 Jun 16;43(12 Suppl S):68S-72S.

22. Glaid A, Yanagisawa M, Langleben D, et al. Expression of endothelin- 1 in the lungs of patients with pulmonary hypertension. N Engl J Med. 1993 Jun 17;328(24):1732-9.

23. Vincent JA, Ross RD, Kassab J, Hsu JM, Pinsky WW. Relation of elevated plasma endothelin in congenital heart disease to increased pulmonary blood flow. Am J Cardiol. 1993 May 15;71(13):1204-7.

24. Steiner MK, Syrkina OL, Kolliputi N, Mark EJ, Hales CA, Waxman AB. Interleukin-6 overexpression induces pulmonary hypertension. Circ Res. $2009 \operatorname{Jan} 30 ; 104(2): 236-44$.

25. Loyd JE, Primm RK, Newman JH. Familial primary pulmonary hypertension: clinical patterns. Am Rev Respir Dis. 1984 Jan;129(1):194-7.

26. Fessel J, Loyd J, Austin E. The genetics of pulmonary arterial hypertension in the post-BMPR2 era. Pulm Circ. 2011 Jul-Sep;1(3):305-19.

27. Trembath R, Thomson J, Machado R, et al. Clinical and molecular genetic features of pulmonary hypertension in patients with hereditary hemorrhagic telangiectasia. NEngl J Med. 2001 Aug 2;345(5):325-34.

28. Umar S, Rabinovitch, Eghbali. Estrogen Paradox in Pulmonary Hypertension. Am J Resp Crit Care Med. 2012 Jul 15;186(2):125-31.

29. Austin ED, Hamid R, Hemnes AR, et al. BMPR2 expression is suppressed by signaling through the estrogen receptor. Biol Sex Differ. 2012 Feb 20;3(1):6.

30. Atkinson C, Stewart S, Upton PD, et al. Primary pulmonary hypertension is associated with reduced pulmonary vascular expression of type II bone morphogenetic protein receptor. Circulation. 2002 Apr 9;105(14):1672-8.

31. Boggaard HJ, Abe K, Vonk Noordegraaf A, Voelkel NF. The right ventricle under pressure: cellular and molecular mechanisms of right heart failure in pulmonary circulation. Chest. 2009 Mar;135(3):794-804.

32. Aguero J, Ishikawa K, Hadri L, et al. Characterization of right ventricular remodeling and failure in a chronic pulmonary hypertension model. Am J Physiol Heart Circ Physiol. 2014 Oct 15;307(8):H1204-15.

33. McLaughlin VV, Archer SL, Badesch DB, et al. ACCF/AHA 2009 expert consensus document on pulmonary hypertension: a report of the American College of Cardiology Foundation Task Force on Expert Consensus 
Documents and the American Heart Association developed in collaboration with the American College of Chest Physicians; American Thoracic Society, Inc.; and the Pulmonary Hypertension Association. J Am Coll Cardiol. 2009 Apr 28;53(17):1573-619.

34. Sciomer S, Badagliacca R, Fedele F. Pulmonary hypertension: echocardiographic assessment. Ital Heart J. 2005;6:840-5.

35. Bossone E, Duong-Wagner TH, Paciocco G, et al. Echocardiographic features of primary pulmonary hypertension. J Am Soc Echocardiogr. 1999 Aug;12(8):655-62.

36. Ling LF, Marwick TH. Echocardiographic assessment of right ventricular function: How to account for tricuspid regurgitation and pulmonary hypertension. JACC Cardiovasc Imaging. 2012 Jul;5(7):747-53.

37. Galiè N, Humbert M, Vachiery JL, et al. 2015 ESC/ERS Guidelines for the diagnosis and treatment of pulmonary hypertension: the Joint Task Force for the Diagnosis and Treatment of Pulmonary Hypertension of the European Society of Cardiology (ESC) and the European Respiratory Society (ERS): Endorsed by: Association for European Paediatric and Congenital Cardiology (AEPC), International Society for Heart and Lung Transplantation (ISHLT). Eur Respir J. 2015 Oct;46(4):903-75.

38. Ryan JJ, Rich JD, Thiruvoipati T, Swamy R, Kim GH, Rich S. Current practice for determining pulmonary capillary wedge pressure predisposes to serious errors in the classification of patients with pulmonary hypertension. Am Heart J. 2012 Apr;163(4):589-94.

39. Tonelli AR, Alnuaimat H, Mubarak K. Pulmonary vasodilator testing and use of calcium channel blockers in pulmonary arterial hypertension. Respir Med. 2010 Apr;104(4):481-96.

40. Barnett CF, Alvarez P, Park MH. Pulmonary Arterial Hypertension: Diagnosis and Treatment. Cardiol Clin. 2016 Aug;34(3):375-89.

41. Boxt LM, Katz J. Magnetic resonance imaging for quantitation of right ventricular volume in patients with pulmonary hypertension. J Thorac Imaging. 1993;8:92-7.

42. Swift AJ, Rajaram S, Condliffe R, et al. Diagnostic accuracy of cardiovascular magnetic resonance imaging of right ventricular morphology and function in the assessment of suspected pulmonary hypertension: results from the ASPIRE registry. J Cardiovasc Magn Reson. 2012 Jun $21 ; 14: 40$

43. Peacock AJ, Crawley S, McLure L, et al. Changes in right ventricular function measured by cardiac magnetic resonance imaging in patients receiving pulmonary arterial hypertension-targeted therapy: the EURO-MR study. Circ Cardiovasc Imaging. 2014 Jan;7(1):107-14.
44. Trip P, Nossent EJ, de Man FS, et al. Severely reduced diffusion capacity in idiopathic pulmonary arterial hypertension: patient characteristics and treatment responses. Eur Respir J. 2013 Dec;42(6):1575-85.

45. Sun XG, Hansen JE, Oudiz RJ, Wasserman K. Pulmonary function in primary pulmonary hypertension. J Am Coll Cardiol. 2003 Mar 19;41(6):1028-35.

46. Jilwan FN, Escourrou P, Garcia G, Jaïs X, Humbert M, Roisman G. High occurrence of hypoxemic sleep respiratory disorders in precapillary pulmonary hypertension and mechanisms. Chest. 2013 Jan;143(1):47-55.

47. Rafanan AL, Golish JA, Dinner DS, Hague LK, Arroliga AC. Nocturnal hypoxemia is common in primary pulmonary hypertension. Chest. 2001 Sep;120(3):894-9.

48. Barst R, Lewis R, Long W, et al. A comparison of continuous intravenous epoprostenol with conventional therapy for primary pulmonary hypertension. N Engl J Med. 1996 Feb 1;334(5):296-301.

49. Galiè N, Corris PA, Frost A, et al. Updated treatment algorithm of pulmonary arterial hypertension. J Am Coll Cardiol. 2013 Dec 24;62(25 Suppl):D60-72.

50. Simonneau G, Barst RJ, Galiè N, et al. Continuous subcutaneous infusion of treprostinil, a prostacyclin analogue, in patients with pulmonary arterial hypertension. Am J Respir Crit Care Med. 2002;165:800-4.

51. Mather M, McDevitt S, Saggar R. Subcutaneous treprostinil in pulmonary arterial hypertension: practical considerations. J Heart Lung Transplant. 2010 Nov;29(11):1210-7.

52. Tapson VF, Gomberg-Maitland M, McLaughlin V, et al. Safety and efficacy of IV treprostinil for pulmonary arterial hypertension: a prospective, multicenter, open-label, 12-week trial. Chest. 2006 Mar;129(3):683-8.

53. McLaughlin VV, Benza RL, Rubin LJ, et al. Addition of inhaled treprostinil to oral therapy for pulmonary arterial hypertension: a randomized controlled clinical trial. J Am Coll Cardiol. 2010 May 4;55(18):1915-22.

54. Jing ZC, Parikh K, Pulido T, et al. Efficacy and safety of oral treprostinil monotherapy for the treatment of pulmonary arterial hypertension: a randomized, controlled trial. Circulation. 2013 Feb 5;127(5):624-33.

55. Tapson VF, Jing ZC, Xu KF, et al. Oral treprostinil for the treatment of pulmonary arterial hypertension in patients receiving background endothelin receptor antagonist and phosphodiesterase type 5 inhibitor therapy (the FREEDOM-C2 study): a randomized controlled trial. Chest. 2013 Sep;144(3):952-8.

56. Olschewski H, Simonneay G, Galiè N, et al. Inhaled iloprost for severe pulmonary hypertension. N Engl J Med. 2002 Aug 1;347(5):322-9. 
57. Mubarak KK. A review of prostaglandin analogs in the management of patients with pulmonary arterial hypertension. Respir Med. 2010 Jan;104(1):9-21.

58. Kuwano K, Hashino A, Asaki T, et al. 2-[4-[(5,6-diphenylpyrazin-2-yl) (isopropyl)amino]butoxy]-N-(methylsulfonyl)acetamide (NS-304), an orally available and long-acting prostacyclin receptor agonist prodrug. J Pharmacol Exp Ther. 2007 Sep;322(3):1181-8.

59. Simonneau G, Lang I, Torbicki A, et al. Efficacy, safety, and tolerability of ACT-293987, a novel oral, non-prostanoid, prostaglandin 12 (IP) receptor agonist: results from a phase lla study in pulmonary arterial hypertension (PAH). Am J Respir Crit Care Med. 2010;181:A2515.

60. Sitbon O, Channick R, Chin KM, et al. Selexipag for the Treatment of Pulmonary Arterial Hypertension. N Engl J Med. 2015 Dec 24;373(26):2522-33.

61. Rubin LJ, Badesch DB, Barst RJ, et al. Bosentan therapy for pulmonary arterial hypertension. N Engl J Med. 2002 Mar 21;346(12):896-903.

62. Galiè N, Olschewski H, Oudiz R, et al. Ambrisentan for the treatment of pulmonary arterial hypertension. Results of the ambrisentan in pulmonary arterial hypertension, randomized, double-blind, placebo-controlled, multicenter, efficacy (ARIES) study 1 and 2. Circulation. 2008 Jun 10;117(23):3010-9.

63. Pulido T, Adzerikho I, Channick RN, et al. Macitentan and morbidity and mortality in pulmonary arterial hypertension. N Engl J Med. 2013 Aug 29;369(9):809-18.

64. Channick RN, Delcroix M, Ghofrani HA, et al. Effect of macitentan on hospitalizations: results from SERAPHIN trial. JACC Heart Fail. 2015 Jan;3(1):1-8.

65. Galiè N, Ghofrani HA, Torbicki A, et al.; Sildenafil Use in Pulmonary Arterial Hypertension (SUPER) Study Group. Sildenafil citrate therapy for pulmonary arterial hypertension. N Engl J Med. 2005 Nov 17;353(20):2148-57.

66. Galiè N, Brundage BH, Ghofrani HA, et al. Tadalafil therapy for pulmonary arterial hypertension. Circulation. 2009 Jun 9;119(22):2894-903.

67. Mathai SC, Hassoun PM, Puhan MA. Sex differences in response to tadalafil in pulmonary arterial hypertension. Chest. 2015 Jan;147(1):188-97.

68. Gabler NB, French B, Strom BL. Race and sex differences in response to endothelin receptor antagonists for pulmonary arterial hypertension. Chest. 2012 Jan;141(1):20-6.
69. Ghofrani HA, Galiè N, Grimminger F, et al. Riociguat for the treatment of pulmonary arterial hypertension. N Engl J Med. 2013 Jul 25;369(4):33040 .

70. Ghofrani HA, Hoeper MM, Halank M, et al. Riociguat for chronic thromboembolic pulmonary hypertension and pulmonary arterial hypertension: a phase II study. Eur Respir J. 2010 Oct;36(4):792-9.

71. Rich S, Kaufmann E, Levy PS. The effect of high doses of calcium-channel blockers on survival in primary pulmonary hypertension. N Engl J Med. 1992 Jul 9;327(2):76-81.

72. Badesch DB, Abman SH, Ahearn GS, et al. Medical therapy for pulmonary arterial hypertension. ACCP evidence-based clinical practice guidelines. Chest. 2004 Jul;126(1 Suppl):35S-62S.

73. Barst RJ, Gibbs SR, Hossein A, et al. Updated evidence-based treatment algorithm in pulmonary arterial hypertension. J Am Coll Cardiol. 2009 Jun 30;54(1 Suppl):S78-84.

74. Sitbon O, Humbert M, Jais X, et al. Long-term response to calcium channel blockers in idiopathic pulmonary arterial hypertension. Circulation. 2005 Jun 14;111(23):3105-11.

75. Taichman DB, Ornelas J, Chung L, et al. Pharmacologic therapy for pulmonary hypertension in adults: CHETS guideline and expert panel report. Chest. 2014 Aug;146(2):449-75.

76. Galiè N, Barbera J, Frost W, et al. Initial use of ambrisentan plus tadalafil in pulmonary arterial hypertension. N Engl J Med. 2015 Aug 27;373:834-44.

77. Hemnes AR, Kiely DG, Cockrill BA, et al. Statement on pregnancy in pulmonary hypertension from the Pulmonary Vascular Research Institute. Pulm Circ. 2015 Sep;5(3):435-65.

78. Jaïs X, Olsson KM, Barberà JA, et al. Pregnancy outcomes in pulmonary arterial hypertension in the modern management era. Eur Respir J. 2012 Oct;40(4):881-5.

79. Lund CJ, Donovan JC. Blood volume during pregnancy: significance of plasma and red cell volumes. Am J Obstetr Gynecol. 1967 Jun 1;98(3):393403.

80. Robson SC, Hunter S, Moore M, Dunlop W. Haemodynamic changes during the puerperium: a Doppler and M-mode echocardiographic study. $\mathrm{Br} \mathrm{J}$ Obstetr Gynaecol. 1987 Nov;94(11):1028-39.

81. Lahm T, Patel KM, Crisostomo PR, et al. Endogenous estrogen attenuates pulmonary artery vasoreactivity and acute hypoxic pulmonary vasoconstriction: the effects of sex and menstrual cycle. Am J Physiol Endocrinol Metab. 2007 Jun 26;293(3):E865-E871. 
82. Mantha S, Karp R, Raghavan V, Terrin N, Bauer KA, Zwicker JI. Assessing the risk of venous thromboembolic events in women taking progestin-only contraception: a meta-analysis. BMJ. 2012 Aug 7;345:e4944.

83. Regitz-Zagrosek V, Lundqvist CB, Borghi C, et al. ESC guidelines on the management of cardiovascular diseases during pregnancy: the Task Force on the Management of Cardiovascular Diseases during Pregnancy of the European Society of Cardiology (ESC). Eur Heart J. 2011 Dec;32(24):314797.

84. Terek D, Kayikcioglu M, Kultursay H, et al. Pulmonary arterial hypertension and pregnancy. J Res Med Sci. 2013 Jan;18(1):73-6. 